\title{
Plant-Extract-Assisted Green Synthesis of Silver Nanoparticles Using Origanum vulgare L. Extract and Their Microbicidal Activities
}

\author{
Mohammed Rafi Shaik ${ }^{1}$ (i), Mujeeb Khan ${ }^{1}$, Mufsir Kuniyil ${ }^{1}{ }^{(1)}$, Abdulrahman Al-Warthan ${ }^{1}$, \\ Hamad Z. Alkhathlan ${ }^{1}$, Mohammed Rafiq H. Siddiqui ${ }^{1}{ }^{(1)}$, Jilani P. Shaik ${ }^{2}$, Anis Ahamed ${ }^{3}$, \\ Adeem Mahmood ${ }^{1}$, Merajuddin Khan ${ }^{1, *}$ and Syed Farooq Adil 1,* (iD \\ 1 Department of Chemistry, College of Science, King Saud University, P.O. Box 2455, \\ Riyadh 11451, Saudi Arabia; rafiskm@gmail.com (M.R.S.); kmujeeb@ksu.edu.sa (M.K.); \\ mufsir@gmail.com (M.K.); awarthan@ksu.edu.sa (A.A.-W.); khathlan@ksu.edu.sa (H.Z.A.); \\ rafiqs@ksu.edu.sa (M.R.H.S.); madeem@ksu.edu.sa (A.M.) \\ 2 Department of Biochemistry, College of Science, King Saud University, Riyadh 11451, Saudi Arabia; \\ jilanibio@gmail.com \\ 3 Department of Botany and Microbiology, College of Science, King Saud University, \\ Riyadh 11451, Saudi Arabia; nanisahamed@gmail.com \\ * $\quad$ Correspondence: mkhan3@ksu.edu.sa (M.K.); sfadil@ksu.edu.sa (S.F.A.); Tel.: +966-11-4675910 (M.K.); \\ +966-11-4670439 (S.F.A.)
}

Received: 8 February 2018; Accepted: 20 March 2018; Published: 22 March 2018

\begin{abstract}
Plant-mediated green synthesis of nanomaterials has been increasingly gaining popularity due to its eco-friendly nature and cost-effectiveness. In the present study, we synthesized silver nanoparticles (AgNPs) by using an aqueous solution of Saudi Origanum vulgare L. plant extract as a bioreducing agent. The as-synthesized AgNPs were characterized using various microscopic and spectroscopic techniques. The results indicated the formation of crystalline face-centered cubic $(f c c)$ AgNPs. Additionally, FT-IR study confirmed that the O. vulgare L. extract not only functioned as a bioreductant but also stabilized the surface of the AgNPs by acting as a capping agent. Moreover, the effect of the amount of the plant extract on the size and the antimicrobial activity of the NPs was also assessed. It was found that with increasing amounts of plant extract, the size of the NPs was decreased. Moreover, as-synthesized AgNPs as well as O. vulgare L. plant extract were separately tested to examine their antimicrobial activities. The activities were tested against various bacterial and fungal microorganisms including Shigella sonnei, Micrococcus luteus, Escherichia coli, Aspergillus flavus, Alternaria alternate, Paecilomyces variotii, Phialophora alba, and so on. These results evidently show that the inclusion of $O$. vulgare L. extracts improves the solubility of AgNPs, which led to a significant enhancement in the toxicity of the NPs against the assessed microorganisms.
\end{abstract}

Keywords: Origanum vulgare L. extract; silver NPs; green synthesis and antimicrobial activity

\section{Introduction}

Due to their extraordinary physicochemical properties, metallic nanoparticles (NPs) have been effectively applied in numerous fields, including health care, synthetic biology, and cellular transportation [1]. Amongst various nanoparticles, AgNPs have received particular attention due to their unique morphologies, stability, and controlled geometry [2]. AgNPs have been largely used in various electronic and sensing devices, coating materials, data packing, and molecular switches [3-5]. Apart from this, they have also been applied in the diagnosis and treatments of various diseases [6]. Particularly, AgNPs possess excellent antimicrobial activities against several microorganisms which 
are known to be responsible for several infectious diseases. Due to this, they have been successfully used in different medical products, such as in coating materials of catheters for cerebrospinal fluid drainage [7-9], contact lenses [9], and other medical devices. They have also been used in bone cement [10], surgical masks, impregnated textile fabrics, nanogels, nanolotions [11-14], wound dressings, etc. [15]. Indeed, a majority of the Ag-based products developed have been commercialized and are approved by global regulatory bodies.

Commonly, AgNPs are synthesized using various chemical and physical methods [16]. The physical approaches include sonication, ball milling, flame pyrolysis, radiation, electric arc discharge, laser ablation, etc. $[17,18]$. These physical approaches frequently entail highly expensive instruments, high temperature and pressure, and high energy consumption [19]. Meanhile, the chemical approaches include condensation, sol gel technique and reduction, and other biochemical approaches. The chemical approach mainly involves the concepts of wet chemistry to prepare AgNPs via the reduction/decomposition of metal salts in solutions using numerous chemical reducing agents [20,21]. However, the chemical methods often require costly metal salts and toxic or hazardous solvents and reductants like sodium borohydride, hydrazine, etc. In addition, different types of stabilizers are also required to prevent the aggregation of particles or to make them physiologically compatible [22-25]. Therefore, these conventional chemical methods have been facing many challenges and have inspired investigators to discover different methods. Besides this, considering the potential of AgNPs for biological applications, the development of simple and environmentally benign approaches for their preparation using nontoxic reagents and solvents under ambient conditions is highly desirable [26,27].

In this context, the concepts of green chemistry have gained immense popularity; these are mainly concerned with replacing chemical products and improving or developing processes and technologies to reduce or even eliminate substances that are harmful to health and the environment [28]. Green chemistry has the most profound implications on the wet chemical synthesis of inorganic NPs [29]. It promotes reactions without hazardous solvents, reducing agents, and stabilizers [30]. Several green methods have been applied so far for the preparation of AgNPs [31] including electrochemical reduction, microwave and sonochemical preparation, or synthesis from supercritical liquids [32-34]. In particular, biomimetic approaches using micro- or marine organisms, proteins, and plant extracts (PE) have become popular for the synthesis of AgNPs due to their biocompatibility [35,36]. Among several biomimetic approaches, the synthesis of AgNPs using plant extracts has become immensely popular. These PE-based methods can be applied as a suitable alternative to the commonly used chemical methods due to their straightforwardness, easy sampling, and low costs, which facilitate the large-scale synthesis of AgNPs.

PE contain a variety of naturally occurring phytomolecules, such as water-soluble flavonoids, alkaloids, and several other phenolic compounds, which are broadly classified as polyphenols [37,38]. These polyphenol-based phytomolecules possess strong reducing properties and have a great tendency to adsorb on the surface of NPs [39]. The antioxidant properties of phenolic phytomolecules are principally owing to their reducing abilities, which enable them to act as reductants and singlet oxygen quenchers. So far, potential sources of phenolic contents have been extensively studied in different categories of plants and plant resources, including leaves, vegetables, fruits, oil seeds, herbs, woofs, and roots, as well as in the extracts of entire plants [40]. Notably, the flavonoids and some other phenolic contents, such as phenolic acids, stilbenes, tannins, and lignin, significantly vary in different parts of same plant; however, these contents are particularly common in leaves, flowering fleshy tissues, and woody types like stems and bark [41].

Besides this, the biologically active phytomolecules existing in the plant extracts effectively promote the synthesis of the AgNPs by acting as reducing agents, and also functionalize the resultant NPs [42]. Furthermore, the phytomolecule-based synthesis and functionalization of AgNPs can be easily carried out under physiological conditions of temperature and pressure [43]. Indeed, due to the dual nature of the phytomolecules, PE-based synthesis qualifies as a best methodology for preparing AgNPs for various biological applications, since the resultant NPs can be directly applied without any 
post treatment [44]. Moreover, these types of reactions can be easily performed without using any sophisticated laboratory facilities and also minimize the use of hazardous chemicals and stabilizers [45]. Therefore, PE-based synthesis of AgNPs clearly satisfies various fundamental guidelines of green chemistry. Thus, the NPs obtained from green methods can be more effective for biological applications when compared with those from chemical methods, and the green methods can also be possibly exploited for large-scale synthesis of AgNPs [46]. It is well established in the literature that the percentage composition of individual constituents of the different parts of the same plants may vary significantly [47]. This may have a considerable effect on the quality of NPs. Therefore, over the years, numerous studies have been reported involving the biosynthesis of AgNPs using extracts of different parts of the plants as reducing agents.

For instance, spherical AgNPs were obtained with the Syzygium cumini fruit extract. The individual biomolecules responsible for AgNP formation were identified as gallic acid, flavonoids, tannins, anthocyanins, and other components [48]. Among these, some flavonoid compounds appear to be responsible for the formation of AgNPs by facilitating the reduction of Ag+ to Ag. In another study, the extract of Cacumen Platycladi was used to prepare AgNPs [49]. In another study, the leaf broth of Arbutus unedo was used as both reducing and stabilizing agent to prepare spherical AgNPs, where the size of AgNPs was between 3 and $20 \mathrm{~nm}$ [50], while the root extract of Erythrina indica was used to prepare spherical AgNPs with size in the range from 20 to $118 \mathrm{~nm}$ [51]. In one of our previous studies, we used Pulicaria glutinosa whole plant extract as a reducing and stabilizing agent for the preparation of AgNPs. The temperature of the reaction and the concentration of the PE had a significant effect on the formation of NPs. Both the size of the nanoparticles and the rate of reaction are much higher at $90{ }^{\circ} \mathrm{C}$ than at room temperature. Also, with increasing concentration of the PE during AgNP synthesis, the solubility of the as-prepared NPs also increased, which showed a linear effect on the antimicrobial activity [42,52].

Apart from this, plants also exhibit a high chemical diversity due to various intrinsic and extrinsic factors such as genetic variations, ecological and environmental factors, etc. [53]. Besides this, different other environmental aspects including temperature, radiation, and photoperiod also play a critical role in defining the quality and quantity of the phytochemical constituents [54]. Therefore, a comparative investigation of the ability of the extracts of the same plant from different origins for the synthesis of nanoparticles is highly desirable. Sankar et al. have demonstrated the synthesis of AgNPs using the aqueous extract of Origanum vulgare from India [55].

In the current study, we have applied Saudi Origanum vulgare L. extract as both bioreductant and capping agent for the green synthesis of silver NPs. O. vulgare L. possesses rich contents of alkaloids, flavonoids, and terpenoids, which contribute greatly to its potential reducing ability. Hence, the PE of O. vulgare L. can be exploited for the green synthesis of metallic NPs. To study the effect of concentration of PE on the quality of NPs, the AgNPs were prepared by using various concentrations of $O$. vulgare L. extract $(1 \mathrm{~mL}, 2.5 \mathrm{~mL}, 5 \mathrm{~mL}$, and $7.5 \mathrm{~mL})$. The green synthesized AgNPs were characterized by several techniques such as UV-Vis, TEM, XRD, FT-IR, and EDX. Moreover, the potential antimicrobial properties of the as-synthesized AgNPs were evaluated against various bacterial and fungal strains, such as Escherichia coli (ATCC 25922), Pseudomonas aeruginosa (ATCC 27584), Salmonella typhimurium (ATCC 14028), Staphylococcus aureus (ATCC 29213), Staphylococcus epidermidis (MTCC 3615), Shigella sonnei (ATCC 11060), Methicillin-resistant Staphylococcus aureus (MRSA) (ATCC 12498), Micrococcus luteus (ATCC 4698), Aspergillus flavus (ATCC 9643), Alternaria alternate (ATCC 13963), Paecilomyces variotii (ATCC 3630), and Phialophora alba (ATCC 9625).

\section{Results and Discussion}

\subsection{UV-Vis Spectral Analysis}

The ecofriendly synthesis of AgNPs was performed under a reflux environment using Saudi O. vulgare L. extract. The Ag+ ion reduction was confirmed by the apparent transformation in the color 
of the reaction mixture from light brown to dark brown. Indeed, no color transformation was noticed in the absence of plant extract, under a similar set of circumstances. The formation of AgNPs was further confirmed by UV-Vis spectral study, which is an authentic technique to monitor the progress of the reaction during the reduction of Ag+ ions. For this purpose, UV-Vis spectra of green synthesized AgNPs prepared at $90{ }^{\circ} \mathrm{C}(\mathrm{OV}-\mathrm{Ag})$ were measured at regular intervals of time as displayed in Figure 1 . The kinetics of the reaction monitored by UV-Vis analysis revealed that the reaction was slow in the beginning; indeed, up to $90 \mathrm{~min}$ from the start of the reaction, no indication of the formation of NPs was observed (no Ag peak). After $90 \mathrm{~min}$, the nucleation was initiated very rapidly and the formation of AgNPs occurred very fast until around $30 \mathrm{~min}$ had passed. This is clearly reflected by the sudden appearance of the characteristic band of AgNPs at $430 \mathrm{~nm}$ after $120 \mathrm{~min}$ of reaction time (red line in Figure 1). The reaction was allowed to continue further and no considerable change was observed in the intensity of the Ag peak, which points towards the completion of the reaction in $~ 120 \mathrm{~min}$.

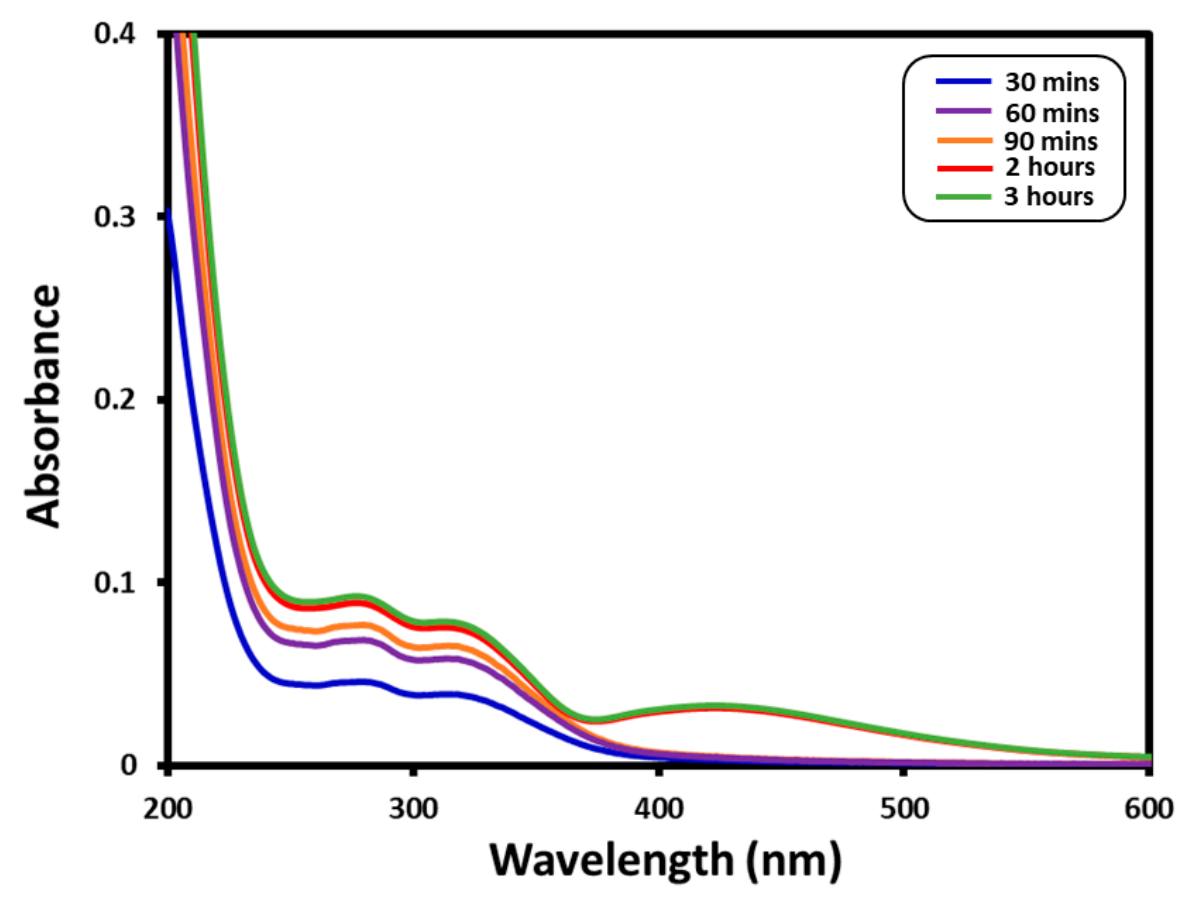

Figure 1. UV-Vis absorption spectra kinetic reaction study of the as-synthesized OV-Ag-1 during the preparation at different time periods.

To assess the effect of plant extract concentration on the synthesis of OV-AgNPs, different samples of OV-AgNPs were synthesized by using various amounts of $\mathrm{O}$. vulgare L. extract. These OV-Ag samples were prepared using $1.0 \mathrm{~mL}$ (OV-Ag-1), $2.5 \mathrm{~mL}$ (OV-Ag-2), $5.0 \mathrm{~mL}$ (OV-Ag-3), and $7.5 \mathrm{~mL}$ (OV-Ag-4), of O. vulgare L. extract taken from the standard solution as revealed in the experimental part. The amount of silver nitrate used was kept fixed in all these tests. Figure 2 demonstrates the UV spectra of AgNPs prepared using different concentrations of plant extract. In our previous study, it was observed that the concentration of P. glutinosa plant extract had a significant effect on the quality of AgNPs. Similarly, O. vulgare PE also exerted a considerable effect on the size of as-prepared AgNPs, which was effectively monitored by the UV analysis. The characteristic UV absorption peak of AgNPs may show a significant shift towards the red end (higher absorption) or the blue end (lower absorption) depending upon the particle size, shape, state of aggregation, and the surrounding dielectric medium [56]. Generally, a broad peak at a higher wavelength indicates an increase in particle size, whereas a narrow line at a shorter wavelength represents smaller particle size. Besides this, other literature reports have also revealed that by increasing the concentration of plant extract, the size and the size distribution of the NPs can be significantly affected [57]. 


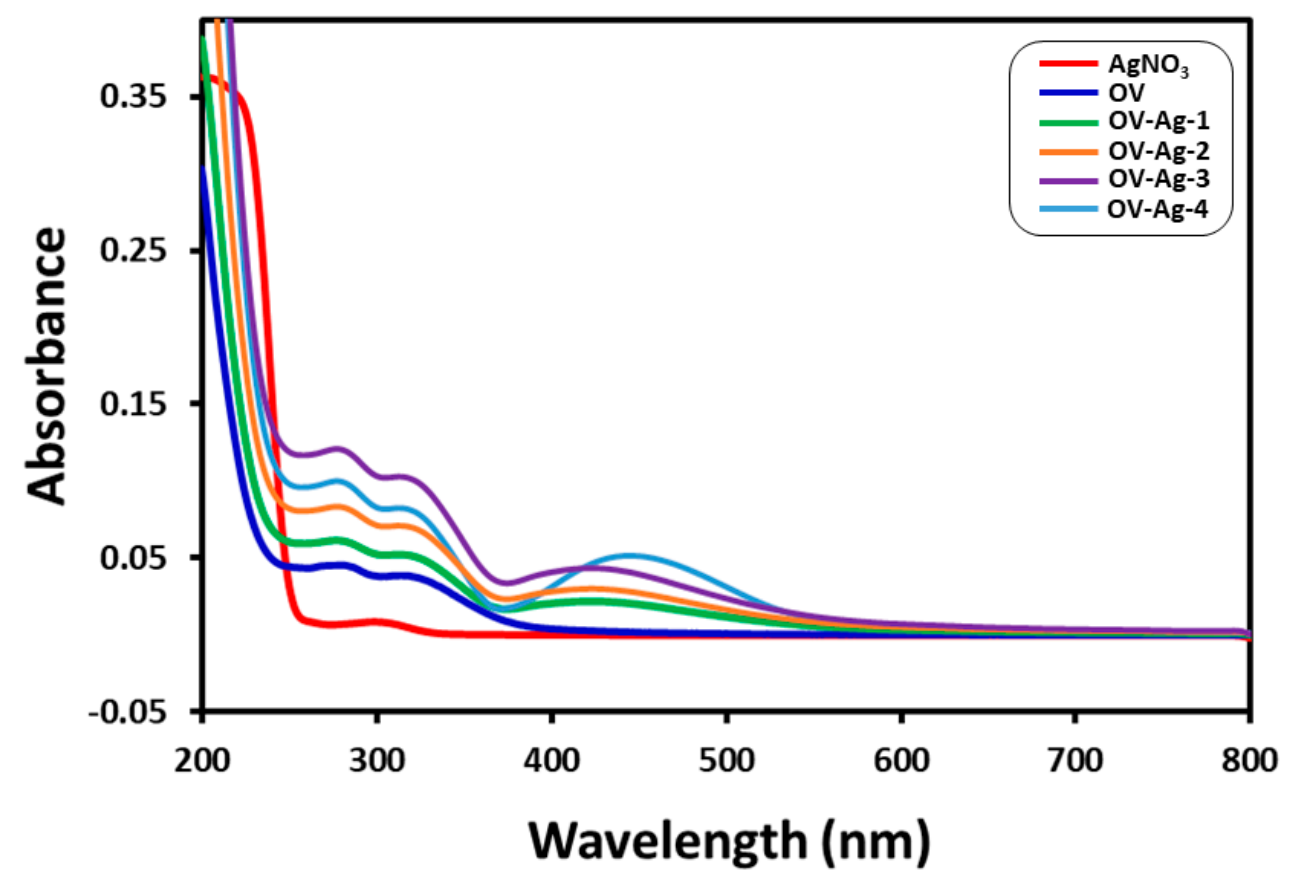

Figure 2. UV-Vis spectral analysis of O. vulgare L. extract (OV), OV-Ag-1, OV-Ag-2, OV-Ag-3, and $\mathrm{OV}-\mathrm{Ag}-4$. All of the reactions were conducted for a duration of $3 \mathrm{~h}$, and the UV-Vis spectral analyses were carried out after sample final workup.

Since the kinetics of the reactions have confirmed that the formation of the AgNPs is completed in a maximum of $3 \mathrm{~h}$, all the concentration-dependent reactions were therefore performed for a duration of $3 \mathrm{~h}$. Figure 2 shows the UV absorption spectra of as-prepared AgNPs at different concentrations of $O$. vulgare plant extract. The AgNPs prepared from a lower concentration of PE $(1 \mathrm{~mL})$ exhibit an absorption band at $\sim 425 \mathrm{~nm}$, which gradually shifted towards the blue region upon increasing the concentration of plant extract up to $2.5(\sim 420 \mathrm{~nm})$ and $5 \mathrm{~mL}(\sim 417 \mathrm{~nm})$. However, when the concentration of plant extract is further increased to $7.5 \mathrm{~mL}$, the absorption band becomes broader and considerably shifted back towards the red region, appearing at $439 \mathrm{~nm}$. This can be attributed to the presence of a large amount of reductants (electron-rich phytomolecules) in the reaction medium, which cause the rapid reduction of $\mathrm{Ag}$ ions. The fast reduction of $\mathrm{Ag}$ ions usually facilitates further growth of NPs by a phenomenon called Ostwald ripening which leads to an increase in the size of NPs. This has ultimately contributed to the large shift of the absorption band towards a higher wavelength. Notably, the AgNPs prepared from $O$. vulgare from other regions exhibited an absorption band at $440 \mathrm{~nm}$, which indicated the formation of larger-sized NPs; however, in this study, the Saudi O. vulgare has produced smaller-sized NPs at a very low concentration of plant extract [55].

Apart from the characteristic peak, the absorption spectrum of as-prepared AgNPs also exhibited two prominent additional peaks at 275 and $320 \mathrm{~nm}$ (cf. Figure 1), which are attributed to the presence of PE phytomolecules bound to the surface of AgNPs as stabilizing ligands. This is further confirmed by measuring the UV spectrum of pristine plant extract (dark blue line, Figure 2), which also showed similar peaks. Moreover, the intensities of the absorption bands at 275 and $320 \mathrm{~nm}$ in the UV spectrum of AgNPs (cf. Figure 2) increases with increasing concentration of the plant extract, which points towards the successful stabilization of the surface of AgNPs by the residual phytomolecules of the plant extract.

\subsection{X-ray Diffraction}

The as-synthesized OV-AgNPs was further analyzed by XRD analysis. The OV-AgNPs diffractogram displayed numerous sharp intense peaks (Figure 3), which not only indicate towards the crystallinity of 
the OV-AgNPs but also confirm the formation of the silver NPs. In particular, the five distinct reflections at $37.5^{\circ}(111), 44.13^{\circ}(200), 63.90^{\circ}(220), 76.85^{\circ}(311)$, and $81.13^{\circ}(222)$ evidently indicate the formation of the face-centered cubic $(f c c)$ structure of the OV-AgNPs. Apart from the characteristic peaks of $f c c$ $\mathrm{Ag}$, the diffractogram also showed several additional intense peaks which remained unassigned in Figure 3. It is suggested that these additional peaks arise due to the crystallization of the bioorganic phase on the surface of the AgNPs. Indeed, this is clearly visible in the TEM images shown below, and also confirmed by the UV and FT-IR analyses. Similarly, additional peaks were also observed in several other studies on the preparation of AgNPs using various extracts. For instance, Tripathy et al. observed various additional peaks in the diffractogram of AgNPs prepared from Azadirachta indica leaf extract [58]. These peaks were attributed to the presence of some bioorganic compounds/protein(s) existing in the neem leaf broth. Indeed, in another study, Shankar et al. confirmed the origin of these peaks from the bioorganic phase by recording the XRD pattern of a film cast from Pelargonium graveolens (Geranium) leaf broth, which was used for the preparation of AgNPs [59]. The authors have suggested that the existence of metal ions (Mg ions) in the metalloprotein chlorophyll within the protein scaffold might have served as strong $\mathrm{X}$-ray scattering centers in the bioorganic crystalline phase.

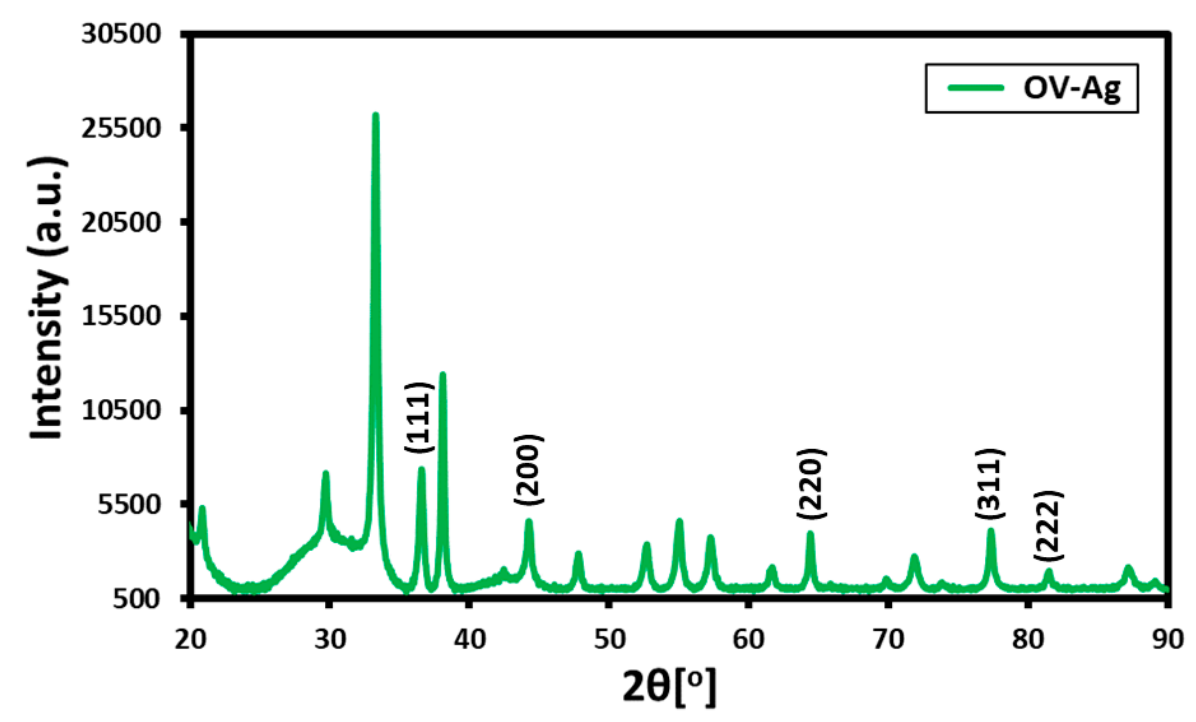

Figure 3. XRD diffractogram of OV-Ag nanoparticles (NPs).

\subsection{TEM and EDX Analysis}

The size and morphology of OV-Ag-4 NPs were evaluated by TEM analysis. Figure 4 a displays an outline of the prepared OV-AgNPs, whereas Figure $4 \mathrm{~b}$ demonstrates the spherical shape of the OV-AgNPs. The nanoparticles are quite polydisperse and ranged in size from 2 to $25 \mathrm{~nm}$ with an average size of ca. $12 \mathrm{~nm}$. Generally, the OV-AgNPs are well dispersed, although some of them were noted to be agglomerated. The TEM images clearly reveal the presence of some organic layer surrounding the surface of the AgNPs. Notably, the majority of the particles in the TEM images are not in physical contact with each other but appeared separated by the organic layer. Therefore, high-resolution TEM images clearly indicate the coating of AgNPs with an organic layer. This is also confirmed by the FT-IR analysis as shown below, which also indicates the presence of several polyphenolic components including flavonoids, terpenoids, etc., which facilitated the reduction of Ag ions and also stabilized the surface of the resultant Ag NPs. Possibly, this thick bioorganic coating surrounding the AgNPs may function as a strong crystalline shell and give rise to sharp Bragg reflections in the XRD pattern. Notably, the size of the AgNPs was found to be too large (63-85 nm) in the case of AgNPs prepared from O. vulgare in an earlier study. Moreover, no TEM were given; we believe that the quality (smaller size and highly stable) of the AgNPs prepared from Saudi O. vulgare 
is far superior when compared with the AgNPs prepared in an earlier study [55]. Additionally, the composition of the elements of the green synthesized silver nanoparticles was also investigated by EDX, and the elemental profile of the OV-AgNPs is displayed in Figure 4d. The intense sharp signal at $3 \mathrm{keV}$ shows that $\mathrm{Ag}$ was the main element. The other signals that were noticed in the range of $0-0.5 \mathrm{KeV}$ signify the characteristic absorption of carbon and oxygen. This clearly indicates the presence of phytoconstituent residual moieties of $O$. vulgare L. extract as a stabilizing agent on the surface of the OV-AgNPs.
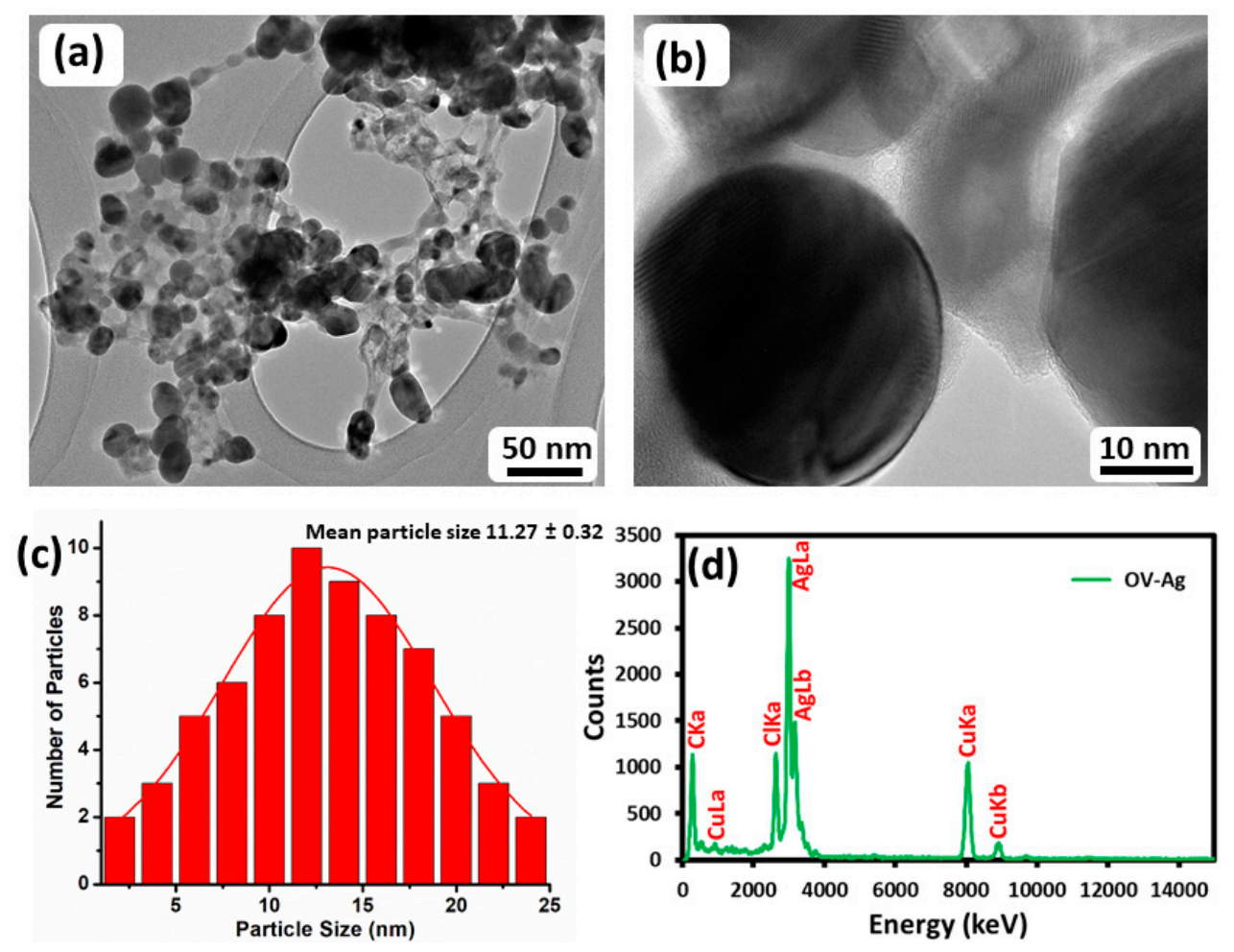

Figure 4. (a,b) High-resolution transmission electron microscopy pictures of the OV-Ag NPs; (c) Particle size distribution graph of OV-AgNPs; and (d) EDX of OV-AgNPs.

\subsection{FT-IR Analysis}

The dual role of the plant extract as a reducing and stabilizing or capping agent was recognized by comparing the FT-IR spectra of pristine O. vulgare L. plant extract and as-synthesized OV-AgNPs as displayed in Figure 5. In order to exclude any possibility of the presence of unbound residual organic moieties, the resultant AgNPs were repeatedly centrifuged and redispersed in DI water. This has clearly reduced the chances of the contribution of phytomolecules to FT-IR, XRD, and TEM results. As presented in Figure 5, the FT-IR analysis of OV-AgNPs is closely identical to the FT-IR spectrum of pristine $O$. vulgare L. extract, excluding some marginal shifts in few peaks. This similarity clearly indicates that some of the residual moieties of the phytomolecules from the O. vulgare L. extract stayed on the surface of the as-synthesized OV-AgNPs. The FT-IR spectrum of O. vulgare L. extract exhibits several absorption peaks at different locations including at $3428 \mathrm{~cm}^{-1}, \sim 2930 \mathrm{~cm}^{-1}, \sim 1610 \mathrm{~cm}^{-1}$, and $\sim 1072 \mathrm{~cm}^{-1}$, which are associated with the several oxygen-comprising functional groups. A majority of the peaks also exist in the FT-IR spectrum of OV-AgNPs with few marginal shifts. For example, all the aforementioned peaks are marginally shifted in the FTIR spectrum of OV-AgNPs and exist at $\sim 3389 \mathrm{~cm}^{-1}, \sim 2923 \mathrm{~cm}^{-1}, \sim 1595 \mathrm{~cm}^{-1}$, and $\sim 1072 \mathrm{~cm}^{-1}$. Consequently, the occurrence of these peaks in the FT-IR spectrum of OV-AgNPs evidently indicates the dual role of the O. vulgare L. extract, both as a green reducing agent and as a stabilizing agent. 


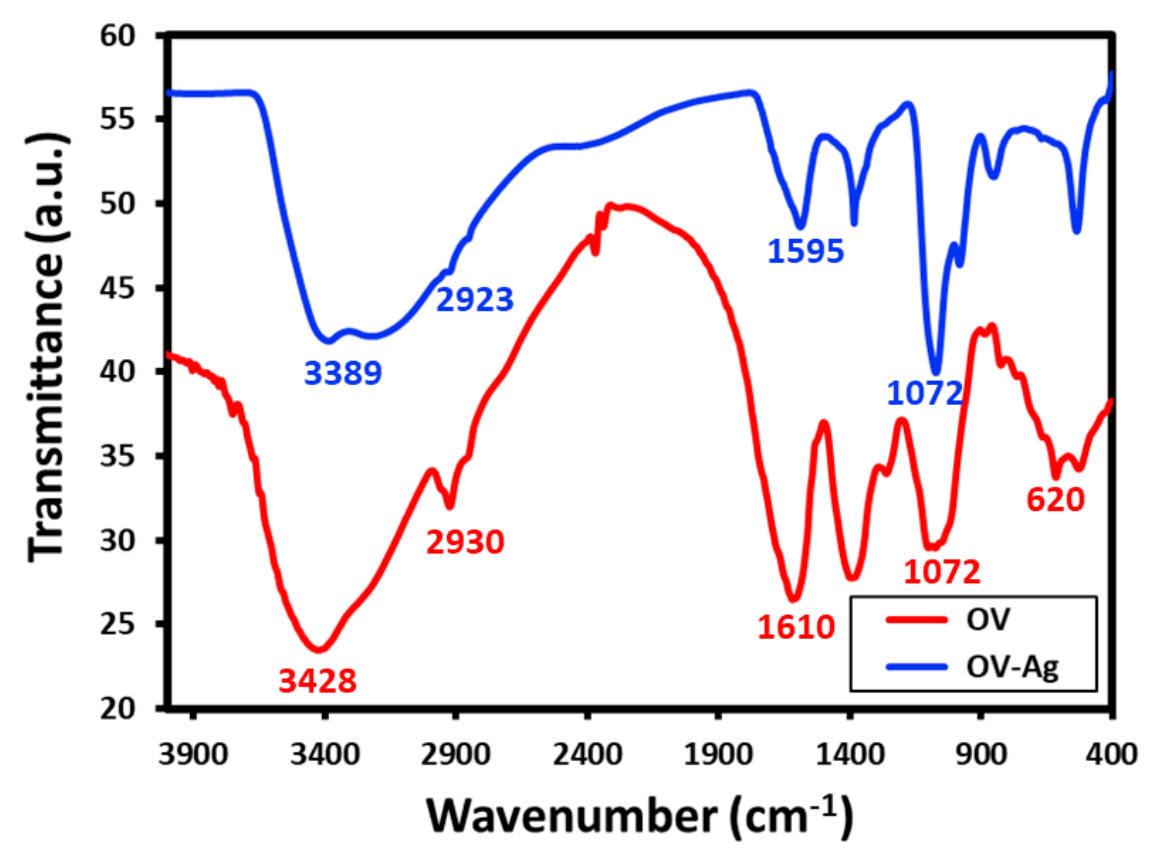

Figure 5. IR spectra of pure O. vulgare L. extract (OV) and green synthesized AgNPs (OV-Ag).

\subsection{Antimicrobial Activity of As-Synthesized OV-AgNPs}

The AgNPs, i.e., OV-AgNPs prepared with employing various concentrations of O. vulgare L. plant extract, were subjected to antimicrobial evaluation against various Gram-positive and Gram-negative bacterial strains as well as fungal strains. During the study, it was found that all the as-prepared NPs displayed significant antimicrobial activity and the results obtained against both Gram-negative (E. coli, P. aeruginosa, S. typhi, and S. sonnei) and Gram-positive (M. luteus, S. epidermidis, Methicillin-resistant Staphylococcus aureus (MRSA), and S. aureus) bacterial strains and pathogenic fungi (A. flavus, A. alternate, P. alba, and P. variotii) are graphically represented as a zone of inhibition (diameter) in Figure 6 and tabulated in Tables 1 and 2. It is apparent from the results that the plant extract does not display any microbicidal activity up to $300 \mu \mathrm{g}$ of plant extract; however, the AgNPs prepared by employing the plant extract display microbicidal activity. It is also observed upon changing the concentration of the PE for the synthesis that there is variation in the microbicidal activity effected by the OV-AgNPs. As the concentration of plant extract increases, the antimicrobial activities of OV-AgNPs also increased significantly. The highest activity was obtained with the OV-AgNPs prepared using $7.5 \mathrm{~mL}$ of plant extract against Gram-positive bacteria, Gram-negative bacteria, and pathogenic fungi. Similar variation in the microbial activity was also observed in our earlier study wherein Pulicaria glutinosa plant extract [52] was employed for the synthesis of AgNPs. This behavior can be attributed to the increased NP solubility due to the larger presence of the plant extract on the surface of the nanoparticles. These phytomolecules played a dual role of both reducing the metal salt and stabilizing the resultant NPs. The increased solubility will enhance the permeation of the nanoparticles through the bacterial cell wall, inducing a disturbance in the cell mitosis metabolism, leading to cell death. In this present study, the OV-Ag-4 displayed the best activity against the tested bacterial and fungal strains, among the AgNPs (OV-Ag-1, OV-Ag-2, OV-Ag-3) prepared. The highest zone of inhibition (19 $\mathrm{mm}$ ) was obtained against $P$. aeruginosa and $S$. aureus, when OV-Ag-4 was employed; however, when the same nanoparticle (i.e., OV-Ag-4) was employed against the fungal strains, A. alternate, the zone of inhibition of $28 \mathrm{~mm}$ was obtained. However, the zone of inhibition was found to be in the range 12-19 $\mathrm{nm}$ for bacterial strains, while a zone of inhibition of $12-28 \mathrm{~nm}$ was obtained when the prepared nanoparticles were employed against fungal strains. 


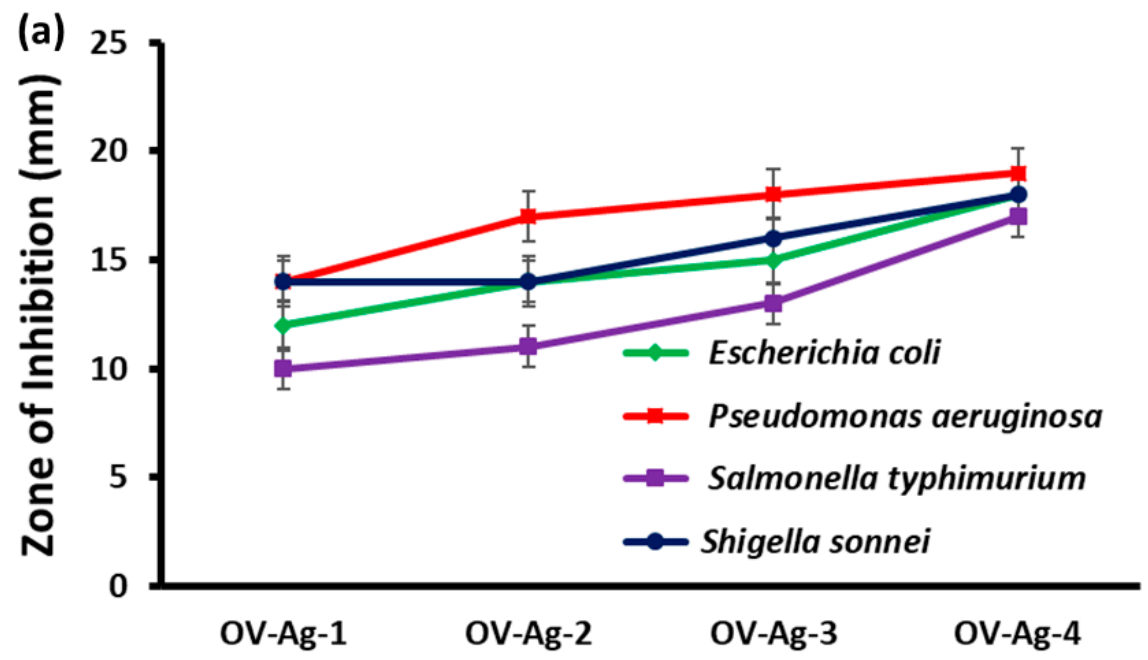

As-synthesized AgNPs using various concentrations of plant extract

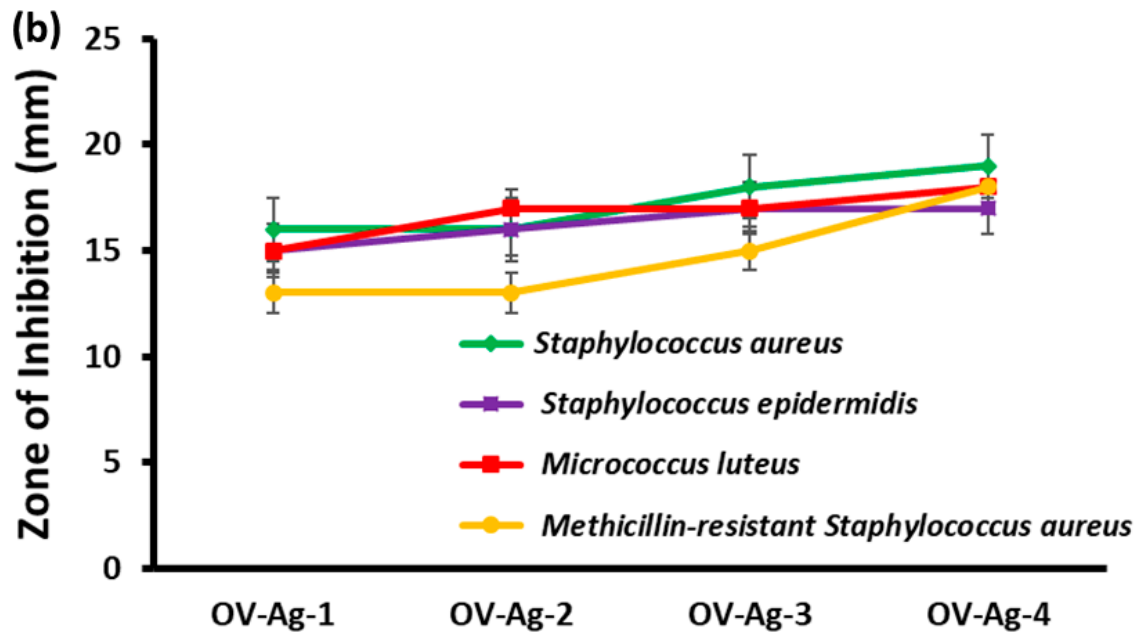

As-synthesized AgNPs using various concentrations of plant extract

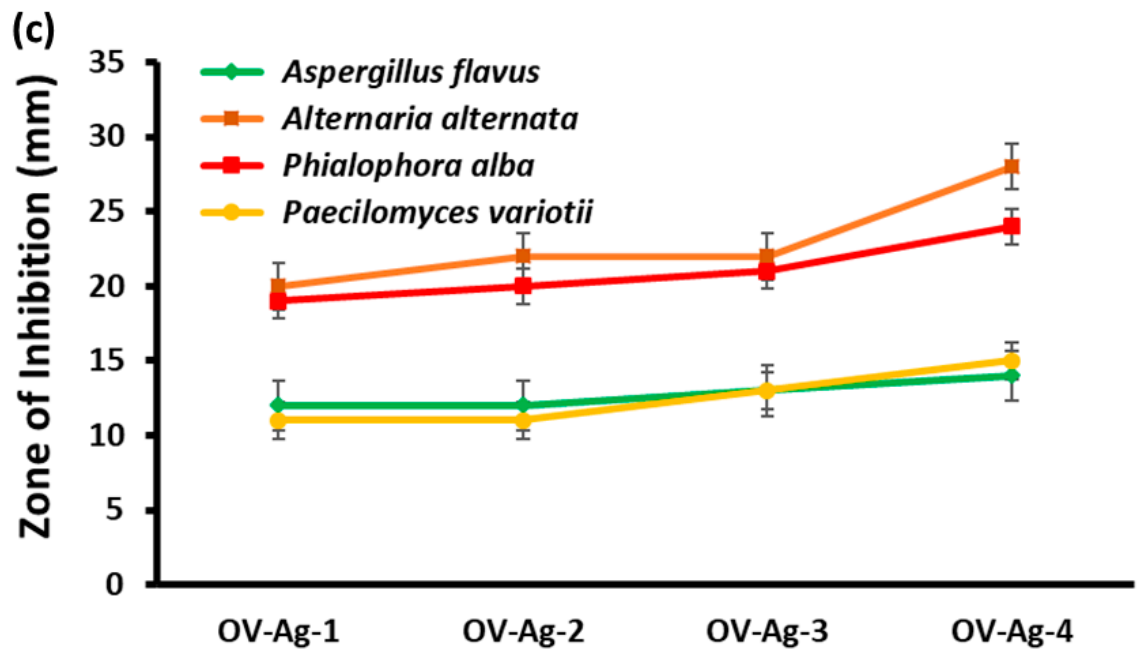

As-synthesized AgNPs using various concentrations of plant extract

Figure 6. Antimicrobial activity of AgNPs against (a) Gram-negative bacteria, (b) Gram-positive bacteria, and (c) pathogenic fungi. 
Table 1. Antibacterial activity of as-synthesized OV-AgNPs with different concentrations of plant extract.

\begin{tabular}{ccccccccc}
\hline & \multicolumn{8}{c}{ Zone of Inhibition (mm) } \\
\cline { 2 - 9 } & \multicolumn{9}{c}{ Gram-Negative } & \multicolumn{3}{c}{ Gram-Positive } \\
\hline Concentration & E. coli & P. aeruginosa & S. typhi & S. sonnei & S. aureus & S. epidermidis & M. luteus & MRSA \\
\hline OV-Ag-1 & 12 & 14 & 10 & 14 & 16 & 15 & 15 & 13 \\
OV-Ag-2 & 14 & 17 & 11 & 14 & 16 & 16 & 17 & 13 \\
OV-Ag-3 & 15 & 18 & 13 & 16 & 18 & 17 & 17 & 15 \\
OV-Ag-4 & 18 & 19 & 17 & 18 & 19 & 17 & 18 \\
\hline
\end{tabular}

Table 2. Antifungal activity of as-synthesized OV-Ag NPs with different concentrations of plant extract.

\begin{tabular}{ccccc}
\hline \multirow{2}{*}{ Concentration } & \multicolumn{4}{c}{ Zone of Inhibition (mm) } \\
\cline { 2 - 5 } & A. flavus & A. alternata & P. alba & P. variotii \\
\hline OV-Ag-1 & 12 & 20 & 19 & 11 \\
OV-Ag-2 & 12 & 22 & 20 & 11 \\
OV-Ag-3 & 13 & 22 & 21 & 13 \\
OV-Ag-4 & 14 & 28 & 24 & 15 \\
\hline
\end{tabular}

\section{Experimental Section}

\subsection{Materials}

$\mathrm{AgNO}_{3}$ was purchased from Sigma Aldrich, MO, USA. O. vulgare L. was obtained from a local herbal market in Riyadh, KSA.

\subsection{Extraction of Plant Extract (PE)}

The plant was obtained in April 2012 and confirmed to have been grown in Al-Kharj (a central province in KSA). The identity of the plant was confirmed by a taxonomist working at King Saud University. During this study, aerial parts of as-purchased O. vulgare L. were used to prepare NPs. To obtain the plant extract, the aerial parts (550 g) were thinly chopped into small pieces and soaked in $2500 \mathrm{~mL}$ of DI water. The resultant mixture was refluxed for several hours (4 h). Subsequently, the aqueous mixture was filtered and dried at $50-60{ }^{\circ} \mathrm{C}$ under vacuum using a rotary evaporator. Finally, a dark brownish color extract $(35.0 \mathrm{~g})$ was obtained, which was stored at $0-4{ }^{\circ} \mathrm{C}$ for further use.

\subsection{Synthesis of Silver Nanoparticles Using O. vulgare L. Extract (OV)}

The silver NPs were prepared by adding $1 \mathrm{~mL}$ of $O$. vulgare L. extract to $49 \mathrm{~mL}$ aqueous solution comprising $85 \mathrm{mg}$ of silver nitrate $(0.5 \mathrm{mM})$ in a $100 \mathrm{~mL}$ round-bottom flask. The round-bottom flask was equipped with a magnetic stir bar and fixed with a cooling condenser. The reaction mixture was stirred for $\sim 2 \mathrm{~h}$ at $85-90^{\circ} \mathrm{C}$. The reaction mixture color transformed instantaneously from light yellow to a dim brown color; afterwards, no color transformation was noticed up to the end of the reaction. The reaction mixture was allowed to cool down, and the reaction mixture was then centrifuged for $30 \mathrm{~min}$ at $9000 \mathrm{rpm}$. Subsequently, the product obtained was washed numerous times with deionized water. Lastly, a black precipitate was formed, which was dried out for $12 \mathrm{~h}$ at $80^{\circ} \mathrm{C}$ in an oven. In order to know the effect of the amount of plant extract on the preparation of AgNPs, a number of experiments were carried out by taking various volumes of plant extract. For instance, numerous experiments were carried out by mixing 1.0, 2.5, 5.0, and $7.5 \mathrm{~mL}$ of $O$. vulgare plant extract (from the stock solution) and $0.5 \mathrm{mmol}$ of $\mathrm{AgNO}_{3}(85 \mathrm{mg})$ in a precise amount of DI water to make up a total quantity of $50 \mathrm{~mL}$. All reactions were performed at $90^{\circ} \mathrm{C}$. The stock solution was prepared by taking $1 \mathrm{gm}$ of plant extract in $10 \mathrm{~mL}$ of DI water. 


\subsection{Microbicidal Activity}

Antimicrobial activity of the OV-AgNPs was examined using standardized inocula of $1-2 \times 10^{7} \mathrm{cfu} / \mathrm{mL}$ with $0.5 \mathrm{McF}$ arland standards introduced onto the surface of sterile agar plates; a streak method was used for even distribution of inocula. The suspension of the organisms in normal saline was inoculated onto the Mueller Hinton Agar plates using a sterile cotton swab and wells (diameter $6 \mathrm{~mm}$, depth $5 \mathrm{~mm}$ ) were prepared using a sterilized cork borer. The plates were incubated for $72 \mathrm{~h}$ at $37^{\circ} \mathrm{C}$ and the zone of inhibition was measured with a ruler. The as-synthesized OV-AgNPs using various concentrations of PE were tested against Gram-positive bacteria, Gram-negative bacteria, and fungi. The following ATCC cultures (bacteria and fungi) were used for the antimicrobial activity: E. coli (ATCC 25922), P. aeruginosa (ATCC 27584), S. typhimurium (ATCC 14028), S. aureus (ATCC 29213), S. epidermidis (MTCC 3615), S. sonnei (ATCC 11060), MRSA (ATCC 12498), M. luteus (ATCC 4698). A. flavus (ATCC 9643), A. alternate (ATCC 13963), P. variotii (ATCC 3630), and P. alba (ATCC 96295). Three replicates of experiments were carried out. The diameter of the zone of inhibition was expressed as mean \pm standard deviation (SD).

\subsection{Characterization}

The as-prepared OV-AgNPs were characterized by UV-Vis spectroscopy (lambda 35, Perkin Elmer, Waltham, MA, USA), FT-IR spectroscopy (1000 FT-IR spectrometer, Perkin Elmer), high-resolution transmission electron microscopy (HRTEM) (JEM 2100F (JEOL, Tokyo, Japan)), energy-dispersive X-ray spectroscopy (EDX) (JEM 2100F (JEOL, Tokyo, Japan)), and X-ray diffraction (D2 Phaser X-ray diffractometer (Bruker, Bavaria, Germany), $\mathrm{Cu} \mathrm{K} \alpha$ radiation $(\lambda=1.5418 \AA)$ ).

\section{Conclusions and Future Implications}

The facile synthesis of AgNPs was carried out using a green reducing agent obtained from O. vulgare $\mathrm{L}$. The characterization results obtained from FT-IR and XRD analyses revealed the presence of plant extract, i.e., O. vulgare L. extract, on the surface of the nanoparticles, indicating that the plant extract was not only efficient in reducing the silver salt to silver nanoparticles but also played a crucial role in stabilizing the obtained nanoparticles. The AgNPs obtained were subjected to biological evaluation and tested against Gram-positive and Gram-negative bacterial strains as well as fungal strains. It was evident that the AgNPs displayed moderate to very good bactericidal and fungicidal properties; however, it was also observed that the microbicidal and fungicidal efficiency varied with the amount of plant extract employed for the preparation of nanoparticles. As the concentration of the plant extract was increased, the AgNPs obtained higher microbicidal and fungicidal activity than did the AgNPs employing lover concentrations of the plant extract. The Ag NPs (i.e., OV-Ag-4) displayed the highest activity against $P$. aeruginosa (Gram-negative strain) and S. aureus (Gram-positive strain) among the various bacterial strains tested. Among the fungal strains tested, it was found to be most effective against $A$. alternate. With future extensions of the present research in mind-and considering the evolution of strains resistant to the present market drugs- - this study can further be extended to include drug-resistant strains in order to shed light on OV-AgNP performance against those strains which shall be reported in the future.

Acknowledgments: The authors extend their appreciation to the Deanship of Scientific Research at King Saud University for funding this work through the research group project No. RG-1436-032.

Author Contributions: Merajuddin Khan, Mujeeb Khan, Mohammed Rafi Shaik and Syed Farooq Adil designed the project. Mohammed Rafi Shaik, Syed Farooq Adil and Mujeeb Khan helped to draft the manuscript. Merajuddin Khan, Adeem Mahmood and Hamad Z. Alkhathlan carried out the preparation of plant extract and characterization of plant extract material. Mohammed Rafi Shaik and Mufsir Kuniyil carried out the experimental part and some of the characterization. Jilani P. Shaik and Anis Ahamed carried out the antimicrobial activity. Abdulrahman Al-Warthan and Mohammed Rafiq H. Siddiqui provided scientific guidance for successful completion of the project and also helped to draft the manuscript. All authors read and approved the final manuscript. 
Conflicts of Interest: The authors declare that they have no competing interests.

\section{References}

1. Burda, C.; Chen, X.; Narayanan, R.; El-Sayed, M.A. Chemistry and properties of nanocrystals of different shapes. Chem. Rev. 2005, 105, 1025-1102. [CrossRef] [PubMed]

2. Grace, A.N.; Pandian, K. Antibacterial efficacy of aminoglycosidic antibiotics protected gold nanoparticles-A brief study. Colloids Surf. A Physicochem. Eng. Asp. 2007, 297, 63-70. [CrossRef]

3. Lee, J.-S. Recent progress in gold nanoparticle-based non-volatile memory devices. Gold Bull. 2010, 43, 189-199. [CrossRef]

4. Van der Molen, S.J.; Liao, J.; Kudernac, T.; Agustsson, J.S.; Bernard, L.; Calame, M.; van Wees, B.J.; Feringa, B.L.; Schönenberger, C. Light-controlled conductance switching of ordered metal-molecule-metal devices. Nano Lett. 2008, 9, 76-80. [CrossRef] [PubMed]

5. Mackowski, S. Hybrid nanostructures for efficient light harvesting. J. Phys. Condens. Matter 2010, $22,193102$. [CrossRef] [PubMed]

6. Khan, A.; Rashid, R.; Murtaza, G.; Zahra, A. Gold nanoparticles: Synthesis and applications in drug delivery. Trop. J. Pharm. Res. 2014, 13, 1169-1177. [CrossRef]

7. Bayston, R.; Ashraf, W.; Fisher, L. Prevention of infection in neurosurgery: Role of "antimicrobial" catheters. J. Hosp. Infect. 2007, 65, 39-42. [CrossRef]

8. Galiano, K.; Pleifer, C.; Engelhardt, K.; Brössner, G.; Lackner, P.; Huck, C.; Lass-Flörl, C.; Obwegeser, A. Silver segregation and bacterial growth of intraventricular catheters impregnated with silver nanoparticles in cerebrospinal fluid drainages. Neurol. Res. 2008, 30, 285-287. [CrossRef] [PubMed]

9. Weisbarth, R.E.; Gabriel, M.M.; George, M.; Rappon, J.; Miller, M.; Chalmers, R.; Winterton, L. Creating antimicrobial surfaces and materials for contact lenses and lens cases. Eye Contact Lens 2007, 33, 426-429. [CrossRef] [PubMed]

10. Alt, V.; Bechert, T.; Steinrücke, P.; Wagener, M.; Seidel, P.; Dingeldein, E.; Domann, E.; Schnettler, R. An in vitro assessment of the antibacterial properties and cytotoxicity of nanoparticulate silver bone cement. Biomaterials 2004, 25, 4383-4391. [CrossRef] [PubMed]

11. Furno, F.; Morley, K.S.; Wong, B.; Sharp, B.L.; Arnold, P.L.; Howdle, S.M.; Bayston, R.; Brown, P.D.; Winship, P.D.; Reid, H.J. Silver nanoparticles and polymeric medical devices: A new approach to prevention of infection? J. Antimicrob. Chemother. 2004, 54, 1019-1024. [CrossRef] [PubMed]

12. Ip, M.; Lui, S.L.; Poon, V.K.; Lung, I.; Burd, A. Antimicrobial activities of silver dressings: An in vitro comparison. J. Med. Microbiol. 2006, 55, 59-63. [CrossRef] [PubMed]

13. Leaper, D.J. Silver dressings: Their role in wound management. Int. Wound J. 2006, 3, 282-294. [CrossRef] [PubMed]

14. Li, Y.; Leung, P.; Yao, L.; Song, Q.; Newton, E. Antimicrobial effect of surgical masks coated with nanoparticles. J. Hosp. Infect. 2006, 62, 58-63. [CrossRef] [PubMed]

15. Atiyeh, B.S.; Costagliola, M.; Hayek, S.N.; Dibo, S.A. Effect of silver on burn wound infection control and healing: Review of the literature. Burns 2007, 33, 139-148. [CrossRef] [PubMed]

16. Sun, Y. Controlled synthesis of colloidal silver nanoparticles in organic solutions: Empirical rules for nucleation engineering. Chem. Soc. Rev. 2013, 42, 2497-2511. [CrossRef] [PubMed]

17. Farias, C.B.; Ferreira Silva, A.; Diniz Rufino, R.; Moura Luna, J.; Gomes Souza, J.E.; Sarubbo, L.A. Synthesis of silver nanoparticles using a biosurfactant produced in low-cost medium as stabilizing agent. Electron. J. Biotechnol. 2014, 17, 122-125. [CrossRef]

18. Van Dong, P.; Ha, C.H.; Kasbohm, J. Chemical synthesis and antibacterial activity of novel-shaped silver nanoparticles. Int. Nano Lett. 2012, 2, 9. [CrossRef]

19. Guzmán, M.G.; Dille, J.; Godet, S. Synthesis of silver nanoparticles by chemical reduction method and their antibacterial activity. Int. J. Chem. Biomol. Eng. 2009, 2, 104-111.

20. Tahir, M.N.; Natalio, F.; Cambaz, M.A.; Panthöfer, M.; Branscheid, R.; Kolb, U.; Tremel, W. Controlled synthesis of linear and branched Au@ ZnO hybrid nanocrystals and their photocatalytic properties. Nanoscale 2013, 5, 9944-9949. [CrossRef] [PubMed]

21. Polavarapu, L.; Liz-Marzán, L.M. Growth and galvanic replacement of silver nanocubes in organic media. Nanoscale 2013, 5, 4355-4361. [CrossRef] [PubMed] 
22. Mourdikoudis, S.; Liz-Marzán, L.M. Oleylamine in nanoparticle synthesis. Chem. Mater. 2013, 25, $1465-1476$. [CrossRef]

23. Montes-García, V.; Pérez-Juste, J.; Pastoriza-Santos, I.; Liz-Marzán, L.M. Metal nanoparticles and supramolecular macrocycles: A tale of synergy. Chem. Eur. J. 2014, 20, 10874-10883. [CrossRef] [PubMed]

24. Erathodiyil, N.; Ying, J.Y. Functionalization of inorganic nanoparticles for bioimaging applications. Acc. Chem. Res. 2011, 44, 925-935. [CrossRef] [PubMed]

25. Castro, L.; Blázquez, M.L.; González, F.G.; Ballester, A. Mechanism and applications of metal nanoparticles prepared by bio-mediated process. Rev. Adv. Sci. Eng. 2014, 3, 199-216. [CrossRef]

26. Marambio-Jones, C.; Hoek, E.M. A review of the antibacterial effects of silver nanomaterials and potential implications for human health and the environment. J. Nanopart. Res. 2010, 12, 1531-1551. [CrossRef]

27. Tran, Q.H.; Le, A.-T. Silver nanoparticles: Synthesis, properties, toxicology, applications and perspectives. Adv. Nat. Sci. Nanosci. Nanotechnol. 2013, 4. [CrossRef]

28. Sheldon, R.A. Fundamentals of green chemistry: Efficiency in reaction design. Chem. Soc. Rev. 2012, 41, 1437-1451. [CrossRef] [PubMed]

29. Duan, H.; Wang, D.; Li, Y. Green chemistry for nanoparticle synthesis. Chem. Soc. Rev. 2015, 44, 5778-5792. [CrossRef] [PubMed]

30. Anastas, P.; Eghbali, N. Green chemistry: Principles and practice. Chem. Soc. Rev. 2010, 39, 301-312. [CrossRef] [PubMed]

31. Hebbalalu, D.; Lalley, J.; Nadagouda, M.N.; Varma, R.S. Greener techniques for the synthesis of silver nanoparticles using plant extracts, enzymes, bacteria, biodegradable polymers, and microwaves. ACS Sustain. Chem. Eng. 2013, 1, 703-712. [CrossRef]

32. Kalathil, S.; Lee, J.; Cho, M.H. Electrochemically active biofilm-mediated synthesis of silver nanoparticles in water. Green Chem. 2011, 13, 1482-1485. [CrossRef]

33. Zaarour, M.; El Roz, M.; Dong, B.; Retoux, R.; Aad, R.; Cardin, J.; Dufour, C.; Gourbilleau, F.; Gilson, J.-P.; Mintova, S. Photochemical preparation of silver nanoparticles supported on zeolite crystals. Langmuir 2014, 30, 6250-6256. [CrossRef] [PubMed]

34. Kessler, M.T.; Hentschel, M.K.; Heinrichs, C.; Roitsch, S.; Prechtl, M.H. Fast track to nanomaterials: Microwave assisted synthesis in ionic liquid media. RSC Adv. 2014, 4, 14149-14156. [CrossRef]

35. Adil, S.F.; Assal, M.E.; Khan, M.; Al-Warthan, A.; Siddiqui, M.R.H.; Liz-Marzán, L.M. Biogenic synthesis of metallic nanoparticles and prospects toward green chemistry. Dalton Trans. 2015, 44, 9709-9717. [CrossRef] [PubMed]

36. Otari, S.; Patil, R.; Waghmare, S.; Ghosh, S.; Pawar, S. A novel microbial synthesis of catalytically active Ag-alginate biohydrogel and its antimicrobial activity. Dalton Trans. 2013, 42, 9966-9975. [CrossRef] [PubMed]

37. Komes, D.; Belščak-Cvitanović, A.; Horžić, D.; Rusak, G.; Likić, S.; Berendika, M. Phenolic composition and antioxidant properties of some traditionally used medicinal plants affected by the extraction time and hydrolysis. Phytochem. Anal. 2011, 22, 172-180. [CrossRef] [PubMed]

38. Quideau, S.; Deffieux, D.; Douat-Casassus, C.; Pouysegu, L. Plant polyphenols: Chemical properties, biological activities, and synthesis. Angew. Chem. Int. Ed. 2011, 50, 586-621. [CrossRef] [PubMed]

39. Rice-evans, C.A.; Miller, N.J.; Bolwell, P.G.; Bramley, P.M.; Pridham, J.B. The relative antioxidant activities of plant-derived polyphenolic flavonoids. Free Radic. Res. 1995, 22, 375-383. [CrossRef] [PubMed]

40. Li, S.; Li, S.-K.; Gan, R.-Y.; Song, F.-L.; Kuang, L.; Li, H.-B. Antioxidant capacities and total phenolic contents of infusions from 223 medicinal plants. Ind. Crops Prod. 2013, 51, 289-298. [CrossRef]

41. Larson, R.A. The antioxidants of higher plants. Phytochemistry 1988, 27, 969-978. [CrossRef]

42. Khan, M.; Khan, M.; Adil, S.F.; Tahir, M.N.; Tremel, W.; Alkhathlan, H.Z.; Al-Warthan, A.; Siddiqui, M.R.H. Green synthesis of silver nanoparticles mediated by Pulicaria glutinosa extract. Int. J. Nanomed. 2013, 8, 1507-1516.

43. Huang, L.; Weng, X.; Chen, Z.; Megharaj, M.; Naidu, R. Green synthesis of iron nanoparticles by various tea extracts: Comparative study of the reactivity. Spectrochim. Acta Part A Mol. Biomol. Spectrosc. 2014, 130, 295-301. [CrossRef] [PubMed]

44. Mie, R.; Samsudin, M.W.; Din, L.B.; Ahmad, A.; Ibrahim, N.; Adnan, S.N.A. Synthesis of silver nanoparticles with antibacterial activity using the lichen Parmotrema praesorediosum. Int. J. Nanomed. 2014, 9, 121-127. [CrossRef] [PubMed] 
45. Nasrollahzadeh, M.; Sajadi, S.M.; Maham, M.; Ehsani, A. Facile and surfactant-free synthesis of Pd nanoparticles by the extract of the fruits of Piper longum and their catalytic performance for the Sonogashira coupling reaction in water under ligand-and copper-free conditions. RSC Adv. 2015, 5, 2562-2567. [CrossRef]

46. Arunachalam, K.D.; Arun, L.B.; Annamalai, S.K.; Arunachalam, A.M. Potential anticancer properties of bioactive compounds of Gymnema sylvestre and its biofunctionalized silver nanoparticles. Int. J. Nanomed. 2015, 10, 31-41. [CrossRef] [PubMed]

47. Khan, M.; Mahmood, A.; Alkhathlan, H.Z. Characterization of leaves and flowers volatile constituents of Lantana camara growing in central region of Saudi Arabia. Arabian J. Chem. 2016, 9, 764-774. [CrossRef]

48. Mittal, A.K.; Bhaumik, J.; Kumar, S.; Banerjee, U.C. Biosynthesis of silver nanoparticles: Elucidation of prospective mechanism and therapeutic potential. J. Colloid Interface Sci. 2014, 415, 39-47. [CrossRef] [PubMed]

49. Huang, J.; Zhan, G.; Zheng, B.; Sun, D.; Lu, F.; Lin, Y.; Chen, H.; Zheng, Z.; Zheng, Y.; Li, Q. Biogenic silver nanoparticles by Cacumen platycladi extract: Synthesis, formation mechanism, and antibacterial activity. Ind. Eng. Chem. Res. 2011, 50, 9095-9106. [CrossRef]

50. Kouvaris, P.; Delimitis, A.; Zaspalis, V.; Papadopoulos, D.; Tsipas, S.A.; Michailidis, N. Green synthesis and characterization of silver nanoparticles produced using Arbutus unedo leaf extract. Mater. Lett. 2012, 76, 18-20. [CrossRef]

51. Sre, P.R.; Reka, M.; Poovazhagi, R.; Kumar, M.A.; Murugesan, K. Antibacterial and cytotoxic effect of biologically synthesized silver nanoparticles using aqueous root extract of Erythrina indica lam. Spectrochim. Acta Part A Mol. Biomol. Spectrosc. 2015, 135, 1137-1144.

52. Khan, M.; Khan, S.T.; Khan, M.; Adil, S.F.; Musarrat, J.; Al-Khedhairy, A.A.; Al-Warthan, A.; Siddiqui, M.R.H.; Alkhathlan, H.Z. Antibacterial properties of silver nanoparticles synthesized using Pulicaria glutinosa plant extract as a green bioreductant. Int. J. Nanomed. 2014, 9, 3551-3565.

53. Vokou, D.; Kokkini, S.; Bessiere, J.-M. Geographic variation of Greek oregano (Origanum vulgare ssp. hirtum) essential oils. Biochem. Syst. Ecol. 1993, 21, 287-295. [CrossRef]

54. Kokkini, S.; Karousou, R.; Vokou, D. Pattern of geographic variations of Origanum vulgare trichomes and essential oil content in Greece. Biochem. Syst. Ecol. 1994, 22, 517-528. [CrossRef]

55. Sankar, R.; Karthik, A.; Prabu, A.; Karthik, S.; Shivashangari, K.S.; Ravikumar, V. Origanum vulgare mediated biosynthesis of silver nanoparticles for its antibacterial and anticancer activity. Colloids Surf. B Biointerfaces 2013, 108, 80-84. [CrossRef] [PubMed]

56. Smitha, S.; Nissamudeen, K.; Philip, D.; Gopchandran, K. Studies on surface plasmon resonance and photoluminescence of silver nanoparticles. Spectrochim. Acta Part A Mol. Biomol. Spectrosc. 2008, 71, 186-190. [CrossRef] [PubMed]

57. Prathna, T.; Chandrasekaran, N.; Raichur, A.M.; Mukherjee, A. Biomimetic synthesis of silver nanoparticles by Citrus limon (lemon) aqueous extract and theoretical prediction of particle size. Colloids Surf. B Biointerfaces 2011, 82, 152-159. [CrossRef] [PubMed]

58. Tripathy, A.; Raichur, A.M.; Chandrasekaran, N.; Prathna, T.; Mukherjee, A. Process variables in biomimetic synthesis of silver nanoparticles by aqueous extract of Azadirachta indica (Neem) leaves. J. Nanopart. Res. 2010, 12, 237-246. [CrossRef]

59. Shankar, S.S.; Ahmad, A.; Sastry, M. Geranium leaf assisted biosynthesis of silver nanoparticles. Biotechnol. Prog. 2003, 19, 1627-1631. [CrossRef] [PubMed]

(C) 2018 by the authors. Licensee MDPI, Basel, Switzerland. This article is an open access article distributed under the terms and conditions of the Creative Commons Attribution (CC BY) license (http:/ / creativecommons.org/licenses/by/4.0/). 